\title{
Elaboração de um recurso educativo para identificação e expressão de emoções ${ }^{1}$
}

\author{
Lucas Cordeiro Freitas ${ }^{2}$ \\ Universidade Federal de São Carlos, São Carlos-SP, Brasil \\ Regina Cavalcanti de Albuquerque Lemmi \\ Universidade de São Paulo, São Paulo-SP, Brasil
}

\begin{abstract}
Resumo: O presente trabalho descreve as etapas de construção e aplicação inicial de um recurso educativo para ser utilizado em programas de Treinamento de Habilidades Sociais com crianças, visando facilitar o ensino das habilidades de identificar, nomear e expressar sentimentos positivos e negativos.

Palavras-chave: habilidades sociais, emoções, intervenção psicológica.
\end{abstract}

\section{Development of educational resource for identification and expression of emotion}

\begin{abstract}
This paper describes the construction and initial testing stages of an educational resource to be used in programs of Social Skills Training with children. The objective of the educational resource is to facilitate teaching skills to identify, nominate and express positive and negative feelings.
\end{abstract}

Keywords: social skills, emotions, psychological intervention.

\section{Elaboración de un recurso educativo para la identificación y expresión de emociones}

\begin{abstract}
Resumen: En este trabajo se describen las etapas iniciales de construcción y ensayo de un recurso educativo que se utilizará en los programas de Entrenamiento de las Habilidades Sociales con los niños, para facilitar la enseñanza de habilidades para identificar, designar y expresar sentimientos positivos y negativos.
\end{abstract}

Palabras clave: habilidades sociales, emociones, intervención psicológica.

As habilidades de identificar, nomear e expressar adequadamente emoções têm sido identificadas na literatura do Treinamento de Habilidades Sociais (THS) como relevantes para um desenvolvimento infantil saudável. A aprendizagem dessas habilidades ocorre nos ambientes de socialização da criança e é modelada pela comunidade verbal à qual ela pertence (Del Prette \& Del Prette, 2005).

Quando as práticas educativas de pais e professores são inefetivas para a promoção de um amplo repertório de habilidades sociais na criança, podem ser necessários programas de THS para a superação de déficits nessa área. Os programas dirigidos a pais e professores podem ser estruturados com o objetivo de aprimorar suas habilidades sociais educativas e/ou sua participação e envolvimento positivo na educação das crianças, que são construtos correlacionados ao repertório de habilidades sociais (Cia, Pamplin, \& Del Prette, 2006; Pinheiro, Haase, Del Prette, Amarante, \& Del Prette, 2006; Del Prette \& Del Prette, 2005).

Com o objetivo de desenvolver um recurso educativo voltado para facilitar o treinamento das habilidades de identificar, nomear e expressar sentimentos em crianças foi elaborado o

1 Os autores agradecem ao Prof. Dr. Almir Del Prette, do Programa de Pós-graduação em Educação Especial da Universidade Federal de São Carlos, pela leitura cuidadosa deste manuscrito.

2 Endereço para correspondência:

Lucas Cordeiro Freitas. Rua Argentina, 461, apto. 38. CEP 13.566-600.

São Carlos-SP, Brasil.E-mail: lucscf@yahoo.com.br
“Jogo das Emoções”, que será descrito no presente trabalho.

\section{Objetivos do jogo}

O recurso educativo denominado "Jogo das emoções" foi desenvolvido para propiciar que crianças em idade escolar discriminem e expressem adequadamente 15 sentimentos diferentes: tristeza, alegria, medo, surpresa, preocupação, vergonha, felicidade, aborrecimento, dor, raiva, desânimo, desapontamento, bom-humor, ciúmes e inveja. Cabe salientar que o conjunto de emoções foi nomeado pelas próprias crianças no processo de elaboração do jogo. Felicidade e alegria foram relatadas como emoções diferentes. Os objetivos específicos do recurso intentam auxiliar a criança a: reconhecer, nomear e expressar as emoções próprias e dos outros; identificar situações e ações associadas às emoções; e expressar compreensão pelo sentimento ou experiência do outro (empatia).

\section{Método}

\section{Participantes}

Participaram da elaboração do jogo 15 meninas com idade entre seis e doze anos, de uma cidade do interior de São Paulo, estudantes da $1^{\mathrm{a}}$ a $6^{\mathrm{a}}$ séries do ensino fundamental de escolas da rede pública. Este grupo se reúne semanalmente para atividades coordenadas por uma ONG (Organização não governamental) há pouco mais de dois anos. Os pais autorizaram a participação das crianças no projeto via assinatura de um Termo de Consentimento Informado. 


\section{Material}

O produto educativo planejado consiste em dois jogos de baralho, um rosa e um azul, com 30 cartas cada. O primeiro baralho (rosa) é composto por 15 cartas com fotos de expressões faciais indicativas de emoções específicas e 15 cartas com desenhos das situações em que tais emoções ocorrem. Nas cartas com as fotos de expressões faciais há uma frase em aberto com o nome da criança fotografada que deve ser completada por outra carta do baralho rosa que contém o desenho da situação na qual a emoção expressada ocorre (por exemplo: "Marciele está

”). Nas cartas que contêm os desenhos das situações, há também frases que descrevem o nome da emoção e a situação em que ela ocorre (por exemplo: "Triste porque seu gato fugiu"). Esses trechos completam a frase iniciada com o nome de cada criança e são, portanto, os pares corretos das outras 15 cartas do baralho rosa.

O segundo baralho (azul) é composto por 15 cartas que contêm fotos individuais de cada uma das crianças do grupo, sem nenhuma expressão facial específica, e 15 cartas com as fotos das encenações de como uma amiga poderia ajudar a outra em cada situação descrita no baralho rosa. Nas cartas com as fotos individuais das crianças há sempre uma frase que precisa ser completada por outra carta do baralho azul (por exemplo: "Daniela pode ser sua amiga ___"). Nas cartas que contêm as fotos das encenações de ajuda, há ainda uma descrição da situação que está sendo representada (por exemplo: "Ajudando a procurar o gato"). As fotos das encenações, juntamente com a sua descrição, completam as outras 15 cartas do baralho azul.

Há ainda uma carta com a foto de todas as crianças juntas que pode ser usada como coringa, ficando no lugar de qualquer carta que esteja faltando para formar uma sequência no jogo.

\section{Procedimento}

\section{Confecção do jogo}

As três primeiras etapas de elaboração do "Jogo das Emoções" foram realizadas com o grupo de crianças em uma única sessão de aproximadamente 90 minutos. A quarta e última etapa foi realizada com o auxílio de um programa de computador e sem a participação das crianças.

\section{Primeira etapa: expressando emoções}

A confecção do jogo iniciou-se com uma conversa da coordenadora com as crianças sobre as emoções. Nesse momento, foram feitas perguntas como: "Quais emoções vocês conhecem e já sentiram?", "Quando vocês sentem estas emoções nomeadas?", "Como é cara de medo, alegria, tristeza?".

Depois dessa conversa inicial, as crianças foram solicitadas a escolher uma emoção para expressarem, em resposta às perguntas iniciais feitas pela coordenadora. Neste momento, a coordenadora assinalou as emoções que ainda poderiam ser escolhidas, para que fossem manifestadas 15 emoções diferentes. Em seguida, foi solicitado que as crianças expressassem as emoções que haviam descrito. As crianças pediam feedback umas às outras sobre a adequação da emoção expressada e quando estavam preparadas, avisavam a coordenadora para que tirasse uma foto da expressão. Enquanto uma criança "preparava" sua expressão, as outras a ajudavam dando dicas como: "cruze o braço", "olha para baixo", "coloca a mão no rosto" e muitas imitavam o que deveria ser feito.

\section{Segunda etapa: relatando a situação da emoção}

Depois da sessão de fotos, foi solicitado que as crianças fizessem um desenho que representasse uma situação hipotética em que haviam experimentado a emoção expressada. Os desenhos foram livres, de acordo com sugestões trocadas entre elas.

\section{Terceira etapa: expressando empatia}

Nesse momento, foi sugerido que as crianças imaginassem como uma amiga poderia "demonstrar amizade" (expressar empatia) quando outra tivesse sentido a emoção expressada. Foi feita uma discussão em grupo sobre esse tópico e várias alternativas foram levantadas, sendo que cada criança escolheu a resposta que esperava da amiga na sua situação. Em seguida, foi solicitado que as crianças, voluntariamente, escolhessem a forma como gostariam de ajudar e de serem ajudadas. Quando ficava estabelecida a ajuda que seria oferecida, era feita uma encenação da situação e a coordenadora a fotografava. Todas as fotos, desenhos e textos confeccionados durante essas três primeiras etapas foram utilizados para a confecção das cartas de baralho do jogo.

\section{Quarta etapa: confeccionando as cartas}

As cartas do baralho foram confeccionadas com o auxílio do programa de computador Corel Draw, no qual foram definidos seus tamanhos e dimensões $(6 \times 9 \mathrm{~cm})$. As cartas foram impressas em papel sulfite colorido rosa e azul e foram coladas as fotos e desenhos das crianças. As fotos utilizadas foram reveladas em tamanho pequeno $(5 \times 7 \mathrm{~cm})$ para que pudessem ser adaptadas às cartas e alguns desenhos foram reduzidos com o auxílio do computador. Em uma última etapa, cada carta foi separadamente plastificada.

\section{Brincando com o jogo}

Finalizadas as etapas da construção do jogo, este foi aplicado em uma sessão de aproximadamente 70 minutos com 12 crianças que participaram da sua elaboração. Os objetivos dessa testagem foram verificar a adequação do jogo aos objetivos propostos e levantar possíveis dificuldades na sua excecução.

\section{Procedimento de aplicação}

O baralho foi testado por meio de dois jogos diferentes. O "Jogo das Emoções I" consistiu em parear as cartas 
rosas com foto/desenho indicando uma emoção e a situação na qual essa emoção está presente. O "Jogo das Emoções II" teve como objetivo formar histórias com quatro cartas (duas rosas e duas azuis) que indicassem a emoção, a situação, o agente da empatia e o comportamento empático.

A aplicação do jogo foi realizada pela própria coordenadora do grupo e registrada em vídeo. Primeiramente, foi formado um grupo de seis crianças para participar do Jogo I e, em um segundo momento, outras seis crianças diferentes foram escolhidas para brincar com o Jogo II. Antes do início do jogo a coordenadora explicou as regras e distribuiu as cartas entre todas as crianças participantes. Em seguida, iniciouse a montagem da sequência das 15 situações do baralho, relacionando a foto do sentimento expressado com nome do sentimento, no caso do Jogo I, e relacionando a agente da ajuda com a ação da ajuda no Jogo II.

\section{Algumas observações}

A aplicação do jogo mostrou que algumas das regras iniciais precisariam ser modificadas para que seus objetivos fossem alcançados plenamente. Observou-se, por exemplo, que a formação de grupos menores agilizaria o jogo, tornando-o menos cansativo. Constatou-se também que as regras poderiam ser mais flexíveis, permitindo às crianças montarem situações diferentes com as cartas, desde que a sequência tivesse lógica e fosse coerente com a emoção manifestada.

\section{Considerações finais}

Deve-se enfatizar que o recurso relatado foi construído para um grupo específico de crianças e que o processo de construção do jogo parece ser, em si mesmo, uma importante etapa para a aprendizagem das habilidades de identificar e expressar emoções. Portanto, a aplicação do recurso a diferentes grupos de crianças necessita passar por alterações substanciais, incluindo, por exemplo, emoções diferentes das que foram apresentadas no presente relato. Sugere-se que a verificação dos efeitos da aplicação do recurso sobre as habilidades de identificar e expressar sentimentos seja realizada por estudos futuros.

\section{Referências}

Cia, F., Pamplin, R. C. O., \& Del Prette, Z. A. P. (2006). Comunicação e participação pais-filhos: Correlação com habilidades sociais e problemas de comportamento dos filhos. Paidéia (Ribeirão Preto), 16, 395-406.

Del Prette, Z. A. P., \& Del Prette, A. (2005). Psicologia das habilidades sociais na infância: Teoria e prática. Petrópolis, RJ: Vozes.

Pinheiro, M. I. S., Haase, V. G., Del Prette, A., Amarante, C. L. D., \& Del Prette, Z. A. P. (2006). Treinamento de habilidades sociais educativas para pais de crianças com problemas de comportamento. Psicologia: Reflexão e Crítica, 19, 407-414.
Lucas Cordeiro Freitas é doutorando do Programa de Pósgraduação em Educação Especial da Universidade Federal de São Carlos.

Regina Cavalcanti de Albuquerque Lemmi é Mestre em Administração de Enfermagem pela Universidade de São Paulo, aluna especial do Programa de Pós-graduação em Educação Especial da Universidade Federal de São Carlos.

Recebido: $12 / 02 / 2008$

$1^{a}$ revisão: $17 / 05 / 2008$

$2^{a}$ revisão: 09/06/2008

$3^{a}$ revisão: 01/08/2008

Aceite final: 16/03/2009 